\title{
Motivational Benefits of Social Support and Behavioural Interventions for Smoking Cessation
}

\author{
Julia N. Soulakova, ${ }^{1}$ Chiung-Ya Tang, ${ }^{1}$ Selena A. Leonardo, ${ }^{1}$ and Lindsay A. Taliaferro ${ }^{2}$ \\ ${ }^{1}$ Burnett School of Biomedical Sciences, College of Medicine, University of Central Florida, Orlando, Florida \\ 2 Department of Internal Medicine, College of Medicine, University of Central Florida, Orlando, Florida
}

\begin{abstract}
T his study examined the role of social support and behavioural interventions used during the last unsuccessful quit attempt for smokers' intentions to quit smoking within the next six months, and identified smokers' attributes associated with the use of social support and behavioural interventions. The analytic sample included 7,195 adult daily smokers who responded to the 2010-2011 Tobacco Use Supplement to the Current Population Survey, conducted in the United States, and indicated having a serious quit attempt in the past 12 months. Smokers who relied on social support from friends and family had higher odds of intending to quit than those who did not $(\mathrm{OR}=1.39,95 \% \mathrm{Cl}=1.22: 1.58)$, and smokers who used interventions had higher odds of intending to quit than those who did not $(\mathrm{OR}=1.36,95 \% \mathrm{Cl}=1.07: 1.74)$. These associations were similar for both sexes, all age groups, and nicotine dependence levels. Both, relying on social support and the use of behavioural interventions were more common among smokers who were female, higher educated, residing in the Western US region, and those who used pharmacological aids for smoking cessation. Social support and behavioural interventions are associated with higher intentions to quit among attempters who relapsed and thus, may aid future smoking cessation.
\end{abstract}

\section{Social Support and Behavioural Interventions for Smoking Cessation} Benefits of Social Support and Behavioural Interventions

Social support plays a critical role in one's psychological and physical well-being. For example, interpersonal relationships can help an individual to deal with stress (Cohen \& Wills, 1985; Villain, Sibon, Renou, Poli, \& Swendsen, 2017), motivate behavioural changes, and help maintain new behaviours (Crookes et al., 2016; House, Landis, \& Umberson, 1988; Sarkar, Taylor, Lai, Shegog, \& Paxton, 2016; Villain et al., 2017). Specifically, having a supportive environment could help a smoker quit smoking and prevent smoking relapse (Creswell, Cheng, \& Levine, 2015; Patten et al., 2016; Sorensen, Emmons, Stoddard, Linnan, \& Avrunin, 2002). For example, daily smokers expecting to receive social support if they quit smoking report stronger intentions to quit smoking (Meijer, Gebhardt, Laar, Kawous, \& Beijk, 2016).

Because of the benefits that social support offers, smokers participating in behavioural interventions for smoking cessation are commonly advised to seek social support from friends and family outside of the program (Baker et al., 2011; Carlson, Goodey, Bennett, Taenzer, \& Koopmans, 2002; Kviz, Crittenden, Clark, Madura, \& Warnecke, 1994; Meijer et al., 2016; Murray, Johnston, Dolce, Lee, \& O'Hara, 1995). These interventions aim to help smokers quit and prevent smoking relapse by providing recommendations for how to cope with psychosocial and/or physical difficulties associated with quitting smoking, such as nicotine withdrawal symptoms.

\section{Study Goals}

Supportive social environments for smoking cessation and evidence-based behavioural interventions for smoking cessation share similar features. In addition, disintegration of individual effects is problematic for those smokers who relied on social support as a part of an intervention or in addition to the intervention. Therefore, the impact of supportive social environments and interventions on quitting behaviours should be assessed

Address for correspondence: Julia N. Soulakova, Burnett School of Biomedical Sciences, College of Medicine, University of Central Florida, 6900 Lake Nona Blvd., Orlando, FL 32827. Email: Julia.soulakova@ucf.edu 
simultaneously. We hypothesize that relying on social support and/or using behavioural interventions, even during a failed quit attempt, will help motivate smokers to improve their intentions to quit in the near future.

The overall goal of the study was to assess whether social support and behavioural interventions used during the last serious (unsuccessful) quit attempt were positively associated with smokers' intentions to quit in the near future. The specific research goals were as follows:

Goal 1: Identify smokers' characteristics associated with relying on social support and behavioural interventions while trying to quit smoking.

Goal 2: Identify specific behavioural interventions associated with the intentions to quit smoking.

Goal 3: Identify whether relying on support and/or using behavioural interventions during the last serious quit attempt are positively associated with smokers' intentions to quit in the near future, and whether these associations differ across diverse groups of smokers with regards to age, sex, and/or nicotine dependence.

\section{Study Behavioural Interventions}

While evidence suggests that behavioural interventions are effective means for smoking cessation (Bully, Sánchez, Zabaleta-Del-Olmo, Pombo, \& Grandes, 2015; Fiore et al., 2008), smokers attempting to quit do not often use behavioural interventions: less than $10 \%$ of attempters use these methods (Cokkinides, Ward, Jemal, \& Thun, 2005; Fiore et al., 1990; Shiffman, Brockwell, Pillitteri, \& Gitchell, 2008a, 2008b; Soulakova \& Crockett, 2016). In this study, we consider the most common behavioural interventions for smoking cessation, which include (1) telephone help-lines or quit-lines, (2) one-on-one counselling, (3) stop smoking clinics, class, or support groups, and (4) internet or web-based programs. All four types of interventions are considered evidence-based and cost-effective (Bernstein, Weiss, Toll, \& Zbikowski, 2016; Cummins, Bailey, Campbell, Koon-Kirby, \& Zhu, 2007; Fiore et al., 2008; Hollis et al., 2007; Lancaster \& Fowler, 2000; Lancaster \& Stead, 2005; Lancaster, Stead, Silagy, \& Sowden, 2000; Schlam et al., 2016). The recommended guidelines for delivery of these interventions have been developed and summarized elsewhere (Fiore et al., 2008; Fiore, Bailey, \& Cohen, 2000).

\section{Factors Associated with the Intentions to Quit}

Several studies examined factors influencing smokers' quit intentions (Fagan \& Augustson, 2007; Feng et al., 2010; Franco, Welsby, Eccleston, \& Furber, 2011; Mathur \& Singh, 2015; Sorensen et al., 2002). For example, for all or almost all examined racial/ethnic groups, longer quit attempts, daily smoking, and receiving advice to quit from a doctor were associated with higher odds of intending to quit (Soulakova, $\mathrm{Li}, \&$ Crockett, 2017). Because smokers' intentions may predict quitting smoking
(Sorensen et al., 2002; Tsoh et al., 2015), these findings concerning smokers' intentions are important. However, whether relying on social support and using behavioural interventions for smoking cessation during an unsuccessful quit attempt help improve smokers' intentions to quit remains unknown.

\section{Method}

\section{Data and Measures}

Data set. The data came from the Tobacco Use Supplement (TUS) survey, one of the largest and commonly used data sources for assessing smoking prevalence and smoking-related behaviours in the United States. Since 1992, the TUS has been administered every three to four years as part of the Current Population Survey (CPS) (US Department of Commerce Census Bureau, 2016). The 2010-2011 TUS-CPS sample is comprised of three monthly samples (May 2010, August 2010, and January 2011). The response rates for self-respondents were about 62\% in May and August 2010, and 60\% in January 2011. The CPS uses a multi-stage design to assure that each monthly sample is representative of the civilian, non-institutionalized US adult population (aged 18 or older) (US Department of Commerce, Census Bureau, 2016). The data represent all 50 US States and the District of Columbia. The states are grouped by region, as is illustrated in Appendix 1. The monthly data and the main and replicate weights are available for public use. The six data files (three monthly data sets and three files with weights) should be downloaded, rescaled, and merged into a single data file, and then used in the analyses as described elsewhere (US Department of Commerce. US Census Bureau, 2012).

The analytic sample consisted of 7,195 reports of current daily smokers. Approximately, $56 \%$ of respondents were surveyed by phone, and $44 \%$ were surveyed inperson. Table 1 presents the socio-demographic characteristics of the sample.

Measures. The primary measure was smoker's intention to quit smoking within the next six months. This measure was defined using yes/no responses to the survey question: 'Are you seriously considering quitting smoking within the next six months?' The moderating factors, relying on social support from friends and family and using behavioural interventions, were defined using yes/no responses to the survey questions formulated similarly to the question 'Thinking back to the last time you tried to quit smoking in the past 12 months, did you use any of the following: Help or support from friends or family?' Four surveyed behavioural interventions included a telephone help-line or quit-line; one-on-one counselling; a stop smoking clinic, class, or support group; and an internet- or web-based program. Using behavioural interventions differentiated between smokers indicating using at least one of these interventions and smokers indicating using none of these interventions. 


\section{Table 1}

Sample description: Smokers' sociodemographic characteristics

\begin{tabular}{|c|c|c|}
\hline Characteristic & Count & Percentage \\
\hline \multicolumn{3}{|l|}{ Age } \\
\hline $18-24$ & 712 & 15.2 \\
\hline $25-44$ & 2,976 & 40.5 \\
\hline $45-64$ & 2,929 & 37.7 \\
\hline $65+$ & 578 & 6.5 \\
\hline \multicolumn{3}{|l|}{ Sex } \\
\hline Male & 3,328 & 51.1 \\
\hline Female & 3,867 & 48.9 \\
\hline \multicolumn{3}{|l|}{ Race/Ethnicity } \\
\hline Non-Hispanic White & 6,068 & 80.2 \\
\hline Non-Hispanic Black & 702 & 11.9 \\
\hline Hispanic & 425 & 7.9 \\
\hline \multicolumn{3}{|l|}{ Education level } \\
\hline Lower educated (high school or below) & 4,049 & 57.1 \\
\hline Higher educated (some college or above) & 3,146 & 42.9 \\
\hline \multicolumn{3}{|l|}{ Region } \\
\hline Northeast & 1,500 & 17.3 \\
\hline Midwest & 2,102 & 28.1 \\
\hline South & 2,287 & 38.1 \\
\hline West & 1,306 & 16.5 \\
\hline \multicolumn{3}{|l|}{ Metropolitan status } \\
\hline Metropolitan area & 5,258 & 80.0 \\
\hline Non-metropolitan area & 1,937 & 20.0 \\
\hline
\end{tabular}

Note. Percentages are based on the population counts. The population count is 9,414,928. The sample size is 7,195 .

Additional (independent) measures involved the following ones. The nicotine dependence measures included (1) night smoking (i.e., waking up at night to smoke; yes, no), (2) smoking within 30 minutes from awakening (yes, no), (3) heavy smoking status, where heavy smoking corresponds to smoking 16 or more cigarettes per day, on average, and non-heavy smoking corresponds to smoking 15 or less cigarettes per day, on average, and (4) smoking status 12 months ago (daily smoker, someday smoker, not a smoker). Validity of these and other measures for nicotine dependence has been previously reported (FrostPineda, Muhammad-Kah, Rimmer, \& Liang, 2014). Characteristics of the last (serious) quit attempt included using pharmacological aids for smoking cessation and duration of the quit attempt. Using pharmacological aids was defined to differentiate among smokers who used at least one pharmacological aid, and those who did not use any aids among the aids assessed: a nicotine patch; a nicotine gum, or nicotine lozenge; a nicotine nasal spray or nicotine inhaler; and medications such as Chantix ${ }^{\circledR}$ or Varenicline; Zyban ${ }^{\circledR}$, Bupropion, or Wellbutrin ${ }^{\circledR}$; and another prescription medication.

\section{Table 2}

Sample description: Social support, behavioural interventions, nicotine dependence, and characteristics of the last quit attempt

\begin{tabular}{lcc}
\hline Characteristics & Count & Percentage \\
\hline Relying on support from friends and family & 2,370 & 32.4 \\
Using behavioural interventions & 610 & 7.4 \\
$\quad$ Telephone help-line or quit-line & 312 & 3.4 \\
One-on-one counselling & 215 & 2.7 \\
Stop smoking clinic, class, or support group & 175 & 2.3 \\
Internet- or web-based program & 150 & 2.0 \\
Nicotine dependence & & \\
Night smoking & 989 & 13.8 \\
Smoking within 30 minutes from awakening & 3,931 & 53.6 \\
Heavy smoking (16+ cigarettes per day) & 2,647 & 35.6 \\
Smoking status 12 months ago & & \\
Daily smoker & 6,312 & 87.4 \\
Occasional smoker & 514 & 7.4 \\
Non-smoker & 369 & 5.2 \\
Characteristics of the last quit attempt & & \\
Duration of the last quit attempt & & \\
Less than 1 day & 981 & 13.3 \\
1-7 days & 3,938 & 54.3 \\
8+ days & 2,276 & 32.3 \\
Using pharmacological aids & 2,798 & 36.0 \\
\hline
\end{tabular}

Note. Percentages are based on the population counts. The total population count is $9,414,928$ and the total sample size is 7,195 .

Duration of the last (serious) quit attempt measure differentiated among attempts that lasted less than one day, attempts that lasted from 1 to 7 days, and attempts of 8 days or longer. This measure was based on responses to the following survey questions. First, a respondent was asked: 'During the past 12 months, have you stopped smoking for one day or longer because you were trying to quit smoking?'. If the respondent answered 'No', then he/she was asked: 'During the past 12 months, have you made a serious attempt to stop smoking because you were trying to quit even if you stopped for less than a day?. If a respondent answered 'Yes' to the former question regarding smoking cessation for at least one day during the past 12 months, he/she was asked: 'The last time you stopped smoking during the past 12 months because you were trying to quit, how long did you stop for?' Table 2 presents summary statistics for the social support measure, behavioural interventions measure, nicotine dependence measures, and characteristics of the last quit attempt.

\section{Statistical Analyses}

Statistical analyses adjusted for the CPS design characteristics were outlined in the Technical Documentation (US Department of Commerce, Census Bureau, 2016). 
Specifically, variance of all estimates was computed via balanced repeated replications with Fay correction of 0.5. Analyses were performed using SAS ${ }^{\circledR 9}$.4 (SAS Institute Inc., 2014).

The initial analyses for assessing all three goals were based on the Rao-Scott chi-square tests (Rao \& Scott, 1981) for contingency tables, where each test was performed at the 5\% significance level. In addition, to assess goal 3, a multiple logistic regression was built to model logit of intending to quit within the next six months (reference level was 'not intending to quit within the next six months'). The main effects included using behavioural interventions, social support, all sociodemographic characteristics depicted in Table 1, i.e., age, sex, race/ethnicity, education status, US region, and metropolitan status of residency, as well as survey mode (phone, in-person), nicotine dependence measures, and characteristics of the last quit attempt depicted in Table 2. The study explored significance of two-way interaction terms between using behavioural interventions and age, sex, and four nicotine dependence measures, and between social support and age, sex, and the nicotine dependence measures. Our initial model contained all main effects and all two-way interactions. Then, in each step, all two-way interactions with $\mathrm{p}$-values exceeding 0.050 were examined, the interaction with the largest p-value was excluded, and the model was refitted. Because all interactions were insignificant and were removed from the model, the final model (Likelihood Ratio $=336,922, \mathrm{df}=22, \mathrm{p}<0.001$ ) contained only the main effects. We report the model-based odds ratios (OR) and corresponding 95\% confidence intervals (CI) based on the final model.

When performing post-hoc comparisons, we used Bonferroni corrections to adjust for multiplicity, and reported the adjusted p-values and simultaneous confidence intervals. For example, if smokers' age was significantly associated with the use of interventions at the 5\% level, then differences in the rates of use of interventions between 18 and 24, 25 and 44, and 44 and 45 year-old smokers relative to $65+$ year-old smokers were assessed. The three latter tests for the relative differences were performed at $1.67 \%$ significance level each.

\section{Results}

\section{Research Goal 1: Smokers' Characteristics Associated with Relying on Social Support and Behavioural Interventions While Trying to Quit Smoking}

Using behavioural interventions was positively associated with relying on social support from friends and family ( $p<0.001)$. Among smokers who used behavioural interventions while trying to quit smoking, $61.6 \%$ relied on support from friends and family, while among smokers who did not use behavioural interventions, only $30.1 \%$ relied on support from friends and family.

Table 3 presents the factors significantly associated with relying on social support and using behavioural interventions. Post-hoc comparisons between different age groups, relative to the $65+$ year-old group, indicated that 18-24 year-old smokers more commonly relied on social support than did $65+$ year-old smokers (adjusted $\mathrm{p}=0.039$, raw $\mathrm{p}=0.013$ ). The other comparisons were not significant. Post-hoc comparisons of non-Hispanic Black and Hispanic smokers, relative to the non-Hispanic White smokers, indicated that non-Hispanic Black smokers less commonly relied on social support than did nonHispanic White smokers (adjusted and raw p's <0.001), while Hispanic and non-Hispanic White smokers were similar in terms of the rates of relying on social support. Comparisons of different US regions of residency to the Western region indicated that the prevalence of relying on social support was significantly lower for smokers residing in the Midwestern (adjusted $p=0.033$, raw $p=0.011$ ) and Southern (adjusted and raw p's $<0.001$ ) regions than it was for smokers residing in the Western region. There was no significant difference between the Northeastern and Western regions.

Table 3 also illustrates that prevalence of using behavioural interventions was higher for female smokers, higher-educated smokers, smokers who used pharmacological aids during the last quit attempt, and smokers who smoked within 30 minutes after awakening. There were no significant associations for the other nicotine dependence measures; the corresponding results are not presented. Post-hoc comparisons among the three groups of duration of the last quit attempt indicated only one significant difference. The prevalence of using behavioural interventions was significantly higher for attempts lasting 8 days or longer than attempts lasting 1 to 7 days (adjusted $\mathrm{p}=0.006$, raw $\mathrm{p}=0.002$ ). Comparisons of different age groups to $65+$ year-old group of smokers indicated only one significant difference: $45-64$ year-old smokers more commonly used behavioural interventions than did 65+ year-old smokers (adjusted $\mathrm{p}=0.042$, raw $\mathrm{p}=0.014$ ). Comparisons of different US regions of residency to the Western region indicated only one significant difference. Smokers residing in the Midwest less commonly used interventions than did smokers residing in the West (adjusted $\mathrm{p}<0.001$, raw $\mathrm{p}<0.001$ ).

\section{Research Goal 2: Specific Behavioural Interventions and Smokers' Intentions to Quit}

Among the four behavioural interventions considered in the study, telephone help/quit-line was the most commonly used (3.4\%), followed by one-on-one counselling $(2.7 \%)$, stop smoking clinic, class, or support group $(2.3 \%)$, and internet- or web-based program $(2.0 \%)$. Figure 1 presents the proportions of smokers intending to quit smoking within the next six months with respect to each surveyed behavioural intervention. As Figure 1 depicts, using an intervention was significantly associated with the higher proportion of smokers intending to quit for all interventions. For example, among smokers who used a phone help-line during the last serious quit attempt, $71.8 \%$ reported intending to quit, while among 


\section{Table 3}

Prevalence of relying on support from friends and family and using behavioural interventions during the last quit attempt

\begin{tabular}{|c|c|c|c|c|}
\hline \multirow[b]{2}{*}{ Characteristic } & \multicolumn{2}{|c|}{ Relying on Social Support } & \multicolumn{2}{|c|}{ Using Behavioural Intervention } \\
\hline & Percentage & $\mathrm{p}$-Value & Percentage & $\mathrm{p}$-Value \\
\hline Age & & $p=0.036$ & & $\mathrm{p}<0.001$ \\
\hline $18-24$ & $36.5 \%$ & & $5.0 \%$ & \\
\hline $25-44$ & $32.6 \%$ & & $6.4 \%$ & \\
\hline $45-64$ & $31.2 \%$ & & $9.6 \%$ & \\
\hline $65+$ & $28.4 \%$ & & $6.2 \%$ & \\
\hline Sex & & $p=0.006$ & & $p=0.003$ \\
\hline Women & $34.2 \%$ & & $8.3 \%$ & \\
\hline Men & $30.7 \%$ & & $6.5 \%$ & \\
\hline Race/ethnicity & & $p<0.001$ & & NS \\
\hline Non-Hispanic White & $34.3 \%$ & & $7.5 \%$ & \\
\hline Non-Hispanic Black & $21.1 \%$ & & $7.1 \%$ & \\
\hline Hispanic & $29.8 \%$ & & $6.4 \%$ & \\
\hline Education level & & $p<0.001$ & & $p<0.001$ \\
\hline Lower educated (high school or below) & $29.6 \%$ & & $6.0 \%$ & \\
\hline Higher educated (some college or above) & $36.1 \%$ & & $9.2 \%$ & \\
\hline Region & & $p=0.003$ & & $\mathrm{p}<0.001$ \\
\hline Northeast & $32.3 \%$ & & $8.0 \%$ & \\
\hline Midwest & $32.4 \%$ & & $6.2 \%$ & \\
\hline South & $30.1 \%$ & & $6.7 \%$ & \\
\hline West & $37.8 \%$ & & $10.5 \%$ & \\
\hline Smoking within 30 minutes after awakening & & NS & & $p=0.004$ \\
\hline Yes & $32.4 \%$ & & $8.3 \%$ & \\
\hline No & $32.4 \%$ & & $6.4 \%$ & \\
\hline Duration of the last quit attempt & & NS & & $p=0.007$ \\
\hline Less than 1 day & $30.0 \%$ & & $7.9 \%$ & \\
\hline Between 1 and 7 days & $32.2 \%$ & & $6.4 \%$ & \\
\hline 8 or more days & $33.7 \%$ & & $8.8 \%$ & \\
\hline Using pharmacological aids & & $p<0.001$ & & $\mathrm{p}<0.001$ \\
\hline Yes & $42.1 \%$ & & $14.9 \%$ & \\
\hline No & $27.0 \%$ & & $3.2 \%$ & \\
\hline
\end{tabular}

Note. Percentages are based on the population counts. The total population count is 9,414,928. The p-values are shown for significant associations; significant results are bolded. NS stands for non-significant.

those who did not use a phone help-line, only $64.6 \%$ reported intending to quit. Similar patterns were found for using one-on-one counselling; a stop smoking clinic, class, or support group; and a(n) internet- or web-based program.

\section{Research Goal 3: Social Support and Behavioural Interventions as Predictors for Smokers' Intentions to Quit}

Relying on social support from friends and family was positively associated with the intentions to quit smoking within the next six months $(\mathrm{p}<0.001)$. Among smokers who relied on social support while trying to quit smoking, $70.7 \%$ intended to quit, while among those who did not rely on social support, only $62.0 \%$ intended to quit. Using behavioural interventions was also positively associated with the intentions to quit smoking within the next six months $(p<0.001)$. Among smokers who used at least one behavioural intervention during the last quit attempt, $74.4 \%$ intended to quit, while only $64.0 \%$ of smokers who did not use behavioural interventions intended to quit.

A lack of significant interactions suggested that the relationships between relying on social support and smokers' intentions to quit, and between using behavioural interventions and smokers' intentions to quit, were similar across smokers' age groups, sex groups, and 


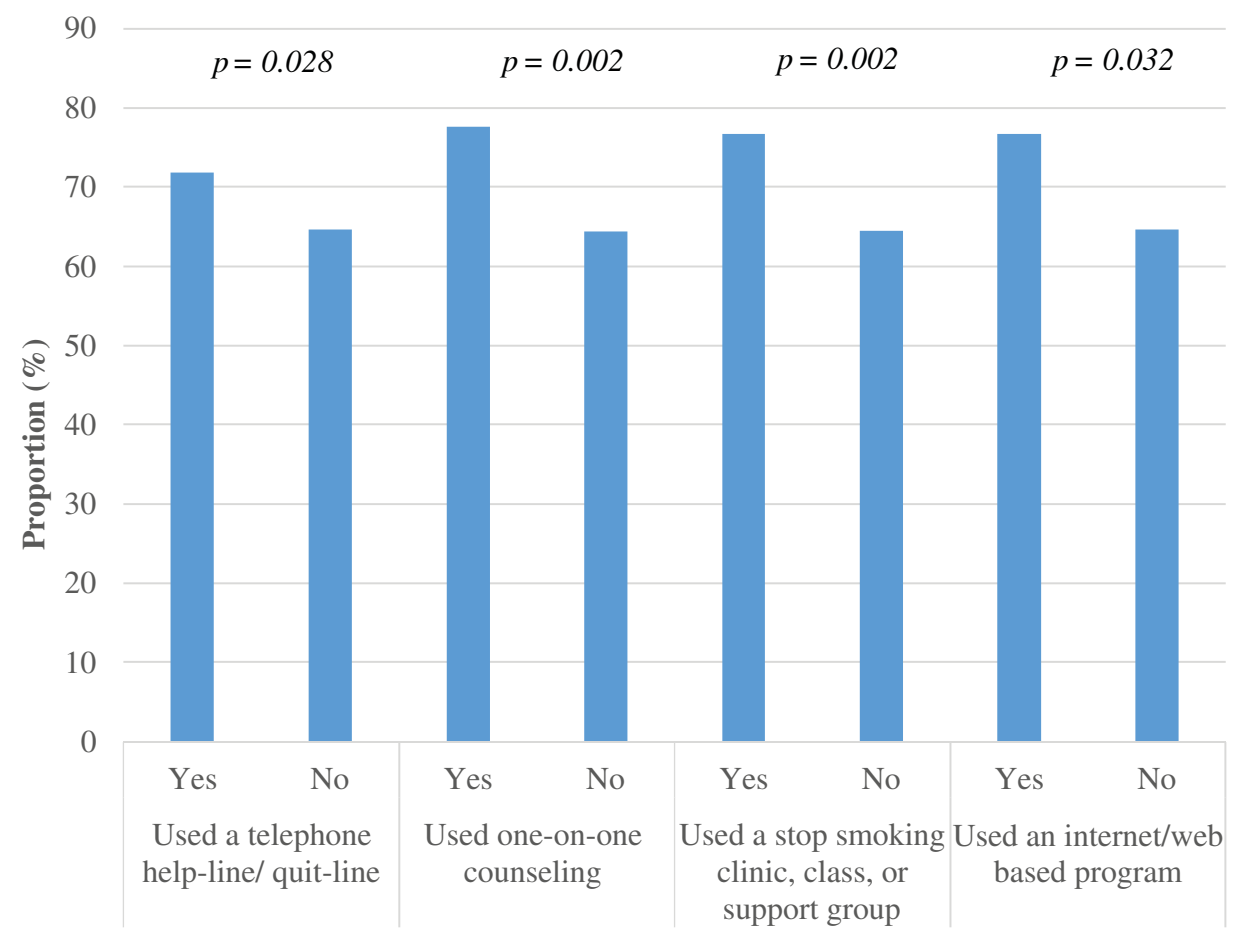

Figure 1

Proportions of smokers (\%) intending to quit among smokers who used and did not use surveyed behavioural interventions.

levels of nicotine dependence (all four nicotine dependence measures). Table 4 depicts results for all significant factors. Specifically, relying on support from friends and family and the use of behavioural interventions during the last quit attempt were positively associated with the intentions to quit smoking within the next six months (both odds ratios were about 1.4, see Table 4).

In addition, heavy smoking was negatively associated with the intentions to quit: light smokers had higher odds of intending to quit than heavy smokers (see Table 4). Prior smoking status was also associated with the intentions to quit: smokers who were daily smokers 12 months ago had lower odds of intending to quit than those who were occasional smokers 12 months ago $(\mathrm{OR}=0.67$, adjusted $\mathrm{p}=0.002,98.3 \% \mathrm{CI}=0.49: 0.92$ ); this was the only significant difference. Table 4 depicts results corresponding to the other significant factors. The specific differences in the rates of smokers intending to quit within the next six months associated with smokers' sociodemographic factors have been addressed elsewhere (e.g., Haug et al., 2010; Mathur \& Singh, 2015; Soulakova et al., 2017) and are not further discussed.

\section{Discussion}

The study's major findings are as follows:

- Social support and behavioural interventions were positively associated with smokers' intentions to quit smoking (even after controlling for other factors influencing smokers' intentions such as nicotine depen- dence, the use of pharmacological methods for smoking cessation, and sociodemographic characteristics).

- The above associations were similar across smokers' age groups, sex groups, and diverse levels of nicotine dependence.

- The odds of intending to quit were $39 \%$ higher for smokers who relied on social support than those who did not and 36\% higher for smokers who used interventions than those who did not. Thus, improvements in smokers' intentions associated with the use of support from friends and family and improvements based on the use of behavioural interventions were comparable, possibly indicating that receiving social support from friends and family may be as important for promoting quitting as using behavioural interventions.

- Relying on social support from friends and family was more common among smokers who used behavioural interventions than those who did not, probably because intervention participants are encouraged to procure different types of support, including support from friends and family, to facilitate cessation (Center for Substance Abuse Treatment, 1999).

The positive associations between the use of social support or behavioural interventions and smokers' intentions to quit smoking observed in this study are consistent with results from prior studies illustrating positive benefits of a supportive environment for motivating smokers to quit (Patten et al., 2016; Rayens, Hahn, \& Hedgecock, 


\begin{tabular}{|c|c|c|}
\hline Factor & Odds Ratio & 95\% Confidence Interva \\
\hline Relying on support from friends and family: Yes versus No $(p<0.001)$ & 1.39 & $(1.22: 1.58)$ \\
\hline Using behavioural interventions: Yes versus No $(p=0.014)$ & 1.36 & (1.07: 1.74) \\
\hline \multicolumn{3}{|l|}{ Age $(p=0.007)$} \\
\hline $18-24$ years old versus $65+$ years old & 1.01 & (0.77: 1.33$)$ \\
\hline $25-44$ years old versus $65+$ years old & 1.31 & (1.06: 1.63) \\
\hline $45-64$ years old versus $65+$ years old & 1.30 & (1.06: 1.59) \\
\hline \multicolumn{3}{|l|}{$\operatorname{Sex}(p<0.001)$} \\
\hline Women versus men & 0.79 & (0.70: 0.90$)$ \\
\hline \multicolumn{3}{|l|}{ Race/ethnicity $(p=0.037)$} \\
\hline Non-Hispanic Black versus non-Hispanic White & 1.31 & (1.06: 1.61) \\
\hline Hispanic versus non-Hispanic White & 1.07 & (0.84: 1.37) \\
\hline Education $(p=0.005)$ : Lower versus higher educated & 0.84 & (0.74: 0.95$)$ \\
\hline \multicolumn{3}{|l|}{ Region $(p=0.012)$} \\
\hline Midwest versus West & 0.79 & (0.66: 0.96$)$ \\
\hline Northeast versus West & 0.75 & $(0.61: 0.92)$ \\
\hline South versus West & 0.73 & $(0.60: 0.89)$ \\
\hline Heavy smoking ( $p<0.001)$ : Light versus heavy smoker (16+ cig/day) & 1.40 & $(1.21: 1.62)$ \\
\hline \multicolumn{3}{|l|}{ Smoking status 12 months ago $(p=0.003)$} \\
\hline Daily smoker versus non-smoker & 0.88 & (0.63: 1.22) \\
\hline Occasional smoker versus non-smoker & 1.31 & $(0.82: 2.09)$ \\
\hline Using pharmacological aids: Yes versus No $(p=0.001)$ & 1.26 & (1.09: 1.44) \\
\hline Survey mode: phone versus in-person $(p=0.007)$ & 1.20 & (1.05: 1.36) \\
\hline
\end{tabular}

2008; Sorensen et al., 2002). The social environment can influence smokers' intentions to quit and quitting behaviours through different mechanisms. For example, support persons could help smokers recognize the importance of quitting, encourage smokers to take responsibility for their actions and behaviours, promote more advantageous substitutions for unhealthy behaviours, and support smokers during relapses and setbacks (Bandura, 2004; Patten et al., 2016; Rayens et al., 2008).

Social support and behavioural interventions were more commonly used by females than males, higher- than lower-educated smokers, and smokers who used pharmacological aids during the quit attempt than those who did not use the aids. Relying on social support also was more common among non-Hispanic White than non-Hispanic Black smokers. Additionally, among the four considered age groups (18-24, 25-44, 45-64, and 65+), smokers aged $65+$ had the lowest rate of relying on social support and the second lowest rate of using behavioural interventions. These results are consistent with research based on the 1996 California Tobacco Survey data, which indicated a decreasing pattern in the rates of using self-help material with age - the rates decreased from 6\% for 18-24 year-old attempters to $2 \%$ for $65+$ year-old attempters (Zhu, Melcer, Sun, Rosbrook, \& Pierce, 2000). One plau- sible explanation for observing these patterns is that social isolation, such as non-participation in community activities and having a small social network, is more common among older smokers, probably due to the lack of financial resources, adverse health conditions, and mobility limitations associated with aging. Lower prevalence of relying on social support and the use of behavioural interventions among elderly (65+ year-old) smokers is consistent with findings that social isolation and perceived social disengagement affect health outcomes among the elderly (Barth, Schneider, \& von Känel, 2010; Bassuk, Glass, \& Berkman, 1999; Cornwell \& Waite, 2009; Steptoe, Shankar, Demakakos, \& Wardle, 2013).

The study also detected some discrepancies in the prevalence of relying on support and using interventions associated with the US region of residency. Specifically, smokers residing in the West reported the highest prevalence of relying on social support (38\% in comparison to $30 \%-32 \%)$ and using behavioural interventions $(11 \%$ in comparison to $6 \%-8 \%)$. These results could suggest the existence of stronger social support environments for smoking cessation and/or better implementation of smoking cessation programs in the Western US region than in other US regions. However, this claim is in need of a more detailed evaluation. 
Based on this study, and prior research cited above, we can make the following recommendations. For tobacco control researchers, policymakers, and clinicians:

- Develop interventions with a social support component tailored to populations who underuse social support while trying to quit smoking, e.g., men, lowereducated smokers, racial/ethnic minorities, and smokers residing in the Southern US region.

- Encourage all smokers to rely on social support from friends and family during quit attempts.

For smokers who want to quit:

- Learn about the harmful impact of smoking and health benefits of quitting.

- Take responsibility for your own actions and behaviours.

- Identify and use more advantageous substitutions for smoking, e.g., walking with a partner.

- Do not become discouraged if a relapse occurs.

For support persons:

- Help smokers recognize the harmful impact of smoking and health benefits of quitting.

- Encourage smokers to take responsibility for their actions and behaviours.

- Hold them accountable for the goals they set for themselves.

- Promote and support more advantageous substitutions for unhealthy behaviours, e.g., walking with a partner.

- Provide support to smokers during relapses and setbacks.

This study included several limitations. First, the current study considered only four specific behavioural interventions (i.e., a telephone help-line or quit-line; one-onone counselling; a stop smoking clinic, class, or support group; and an internet- or web-based program) and did not consider other behavioural interventions, such as text messaging or smartphone applications (Baskerville et al., 2015; Ubhi, Michie, Kotz, Wong, \& West, 2015). This limitation may pose a difficulty for comparing results with those from other studies. Second, our findings indicated that social support from friends and family was more prevalent among those attempters who used behavioural interventions. While we used two different survey items to assess the use of social support from friends/family and behavioural interventions, the effects of each factor on intentions cannot be completely disintegrated. Third, those attempters who indicated using behavioural interventions and not relying on support from their friends and family members could have used another form of social support as a part of the intervention, e.g., support from the group members or counsellors. The benefits of other types of support were not addressed in this study. Fourth, the social support measure was not validated in prior studies; therefore, one might question accuracy and validity of this measure. A fifth limitation pertains to the inclusion of all reported serious quit attempts, including attempts selfidentified as serious and lasting less than one day. These attempts could be different from the attempts termed 'serious' in other studies, e.g., commonly a serious quit attempt is defined as an attempt lasting one day or longer (Cokkinides et al., 2005; Zhou, Nonnemaker, Sherrill, \& Gilsenan, 2009). While the percentage of short attempts in the sample was relatively small (only 13\%), exclusion of these attempts from analyses could, potentially, change the study results, e.g., impact of behavioural interventions on smokers' intentions could become more pronounced than the impact of social support. Finally, due to the observational nature of the data, results from the current study should not be used to suggest a causal relationship between smokers' behaviours during the last (unsuccessful) quit attempt and their intentions to quit smoking.

The findings regarding benefits of support from close friends and family may suggest the capacity of these support persons to understand what their friend/loved one needs and provide what is needed to increase the smoker's intention to quit (Mak, Ho, \& Day, 2013; Patten et al., 2016; Rayens et al., 2008). Additional research is needed to confirm this hypothesis. Future research also should examine the role of social support in treatment utilization (behavioural and pharmacological) and smokers' intentions to quit, as well as examine more detailed information about the duration and intensity of interventions and social support used and the order in which they were used.

The study results suggest that smokers' intentions to quit may be different depending on their experiences during their last failed quit attempt. Because intending to quit in the near future has been found to be associated with quit attempts and eventual smoking cessation (Baker et al., 2011; Dhumal et al., 2014; Feng et al., 2010; Mathur \& Singh, 2015), motivating smokers to seek and utilize social support and behavioural interventions, while trying to quit smoking, may help increase the rate of successful quit attempts and decrease the prevalence of smoking cessation.

\section{Acknowledgement}

We would like to thank the Editor and Reviewers for providing us with their constructive comments that helped us improve the paper.

\section{Funding}

Research reported in this publication was supported by the National Institute on Minority Health and Health Disparities of the National Institutes of Health under Award Number R01MD009718. The content is solely the responsibility of the authors and does not necessarily represent the official views of the National Institutes of Health. 


\section{Conflict of Interest}

None.

\section{Ethical Standards}

The authors assert that all procedures contributing to this work comply with the ethical standards of the relevant national and institutional committees on human experimentation and with the Helsinki Declaration of 1975, as revised in 2008.

\section{Appendix 1}

\begin{tabular}{|c|c|c|c|}
\hline \multicolumn{4}{|c|}{ Composition of the US States and Regions } \\
\hline Northeastern & Midwestern & Southern & Western \\
\hline Region & Region & Region & Region \\
\hline Connecticut & Illinois & Alabama & Alaska \\
\hline Maine & Indiana & Arkansas & Arizona \\
\hline Massachusetts & lowa & Delaware & California \\
\hline New Hampshire & Kansas & District of Columbia & Colorado \\
\hline New Jersey & Michigan & Florida & Hawaii \\
\hline New York & Minnesota & Georgia & Idaho \\
\hline Pennsylvania & Missouri & Kentucky & Montana \\
\hline Rhode Island & Nebraska & Louisiana & Nevada \\
\hline \multirow[t]{9}{*}{ Vermont } & North Dakota & Maryland & New Mexico \\
\hline & Ohio & Mississippi & Oregon \\
\hline & South Dakota & North Carolina & Utah \\
\hline & Wisconsin & Oklahoma & Washington \\
\hline & & South Carolina & Wyoming \\
\hline & & Tennessee & \\
\hline & & Texas & \\
\hline & & Virginia & \\
\hline & & West Virginia & \\
\hline
\end{tabular}

\section{References}

Baker, T. B., Mermelstein, R., Collins, L. M., Piper, M. E., Jorenby, D. E., Smith, S. S. et al. (2011). New methods for tobacco dependence treatment research. Annals of Behavioral Medicine, 41(2), 192-207. https://doi.org/10.1007/ s12160-010-9252-y.

Bandura, A. (2004). Health promotion by social cognitive means. Health Education \& Behavior, 31(2), 143-164. https: //doi.org/10.1177/1090198104263660.

Barth, J., Schneider, S., \& von Känel, R. (2010). Lack of social support in the etiology and the prognosis of coronary heart disease: A systematic review and meta-analysis. Psychosomatic Medicine, 72(3), 229-238. https://doi.org/10. 1097/PSY.0b013e3181d01611.

Baskerville, N. B., Struik, L. L., Hammond, D., Guindon, G. E., Norman, C. D., Whittaker, R. et al. (2015). Effect of a mobile phone intervention on quitting smoking in a young adult population of smokers: Randomized controlled trial study protocol. JMIR Research Protocols, 4(1), e10. https://doi.org/ 10.2196/resprot.3823.

Bassuk, S. S., Glass, T. A., \& Berkman, L. F. (1999). Social disengagement and incident cognitive decline in community-dwelling elderly persons. Annals of Internal Medicine, 131(3), 165. https://doi.org/10.7326/ 0003-4819-131-3-199908030-00002.

Bernstein, S. L., Weiss, J.-M., Toll, B., \& Zbikowski, S. M. (2016). Association between utilization of quitline services and probability of tobacco abstinence in low-income smokers. Journal of Substance Abuse Treatment, 71, 58-62. https://doi. org/10.1016/j.jsat.2016.08.014.

Bully, P., Sánchez, Á., Zabaleta-Del-Olmo, E., Pombo, H., \& Grandes, G. (2015). Evidence from interventions based on theoretical models for lifestyle modification (physical activity, diet, alcohol and tobacco use) in primary care settings: A systematic review. Preventive Medicine, 76, 576-593. https://doi.org/10.1016/j.ypmed.2014.12.020.

Carlson, L.E., Goodey, E., Bennett, M. H., Taenzer, P., \& Koopmans, J. (2002). The addition of social support to a community-based large-group behavioral smoking cessation intervention: Improved cessation rates and gender differences. Addictive Behaviors, 27(4), 547-559. https:/doi. org/10.1016/S0306-4603(01)00192-7.

Center for Substance Abuse Treatment. (1999). Enhancing motivation for change in substance abuse treatment. Treatment Improvement Protocol (TIP) Series, No. 35. HHS Publication No. (SMA)13-4212. Rockville, MD: Substance Abuse and Mental Health Services Administration. Available online at https://store.samhsa.gov/shin/content/SMA13-4212/ SMA13-4212.pdf

Cohen, S., \& Wills, T. A. (1985). Stress, social support, and the buffering hypothesis. Psychologkal Bulletin Cassel, 98(31), 310-357.

Cokkinides, V. E., Ward, E., Jemal, A., \& Thun, M. J. (2005). Under-use of smoking-cessation treatments: Results from the national health interview survey, 2000. American Journal of Preventive Medicine, 28, 119-122. https://doi.org/10. 1016/j.amepre.2004.09.007.

Cornwell, E. Y., \& Waite, L. J. (2009). Social disconnectedness, perceived isolation, and health among older adults. Journal of Health and Social Behavior, 50(1), 31-48. https://doi.org/ 10.1177/002214650905000103.

Creswell, K. G., Cheng, Y., \& Levine, M. D. (2015). A test of the stress-buffering model of social support in smoking cessation: Is the relationship between social support and time to relapse mediated by reduced withdrawal symptoms? Nicotine \& Tobacco Research, 17(5), 566-571. https://doi.org/10. 1093/ntr/ntu192.

Crookes, D. M., Shelton, R. C., Tehranifar, P., Aycinena, C., Gaffney, A. O., Koch, P. et al. (2016). Social networks and social support for healthy eating among Latina breast cancer survivors: Implications for social and behavioral interventions. Journal of Cancer Survivorship, 10, 291-301. https: //doi.org/10.1007/s11764-015-0475-6.

Cummins, S. E., Bailey, L., Campbell, S., Koon-Kirby, C., \& Zhu, S.-H. (2007). Tobacco cessation quitlines in North America: 
A descriptive study. Tobacco Control, 16(Suppl. 1), i9-i15. https://doi.org/10.1136/tc.2007.020370.

Dhumal, G. G., Pednekar, M. S., Gupta, P. C., Sansone, G. C., Quah, A. C. K., Bansal-Travers, M. et al. (2014). Quit history, intentions to quit, and reasons for considering quitting among tobacco users in India: Findings from the Tobacco control policy evaluation India Wave 1 Survey. Indian Journal of Cancer, 51(Suppl. 1), S39-S45. https://doi.org/10. 4103/0019-509X.147467.

Fagan, P., \& Augustson, E. (2007). Quit attempts and intention to quit cigarette smoking among young adults in the United States. Journal of Public, 97(8):1412-1420. Retrieved from http://ajph. aphapublications.org/doi/abs/10.2105/ AJPH.2006.103697.

Feng, G., Jiang, Y., Li, Q., Yong, H.-H., Elton-Marshall, T., Yang, J. et al. (2010). Individual-level factors associated with intentions to quit smoking among adult smokers in six cities of China: Findings from the ITC China Survey. Tobacco Control, 19(Suppl. 2), i6-i11. https://doi.org/10.1136/tc.2010. 037093.

Fiore, M. C., Novotny, T. E., Pierce, J. P., Giovino, G. A., Hatziandreu, E. J., Newcomb, P. A. et al. (1990). Methods used to quit smoking in the United States. Do cessation programs help? JAMA, 263(20), 2760-2765.

Fiore, M., Bailey, W., \& Cohen, S. (2000). Treating tobacco use and dependence: Clinical practice guideline. Rockville, MD: US Department of Health and Human Services. Retrieved from http://lib.adai.washington.edu/dbtw-wpd/exec/dbtwpub. dll?BU=http\%3A//lib.adai.washington.edu/ebpsearch. $\mathrm{htm} \& \mathrm{TN}=\mathrm{EBP} \& \mathrm{QY}=$ Find + Access $\mathrm{No}=50 \& \mathrm{RF}=$ Full + Display $\& D F=F u l l+$ Display $\& N P=3 \& R L=1 \& D L=0 \& X C=$ $/ \mathrm{dbtw}-\mathrm{wpd} / \mathrm{exec} / \mathrm{db}$ twpub.dll\&AC$=\mathrm{QBE} \_\mathrm{QUERY} \& \mathrm{CS}=0$.

Fiore, M., Jaen, C., Baker, T., Bailey, W., Benowitz, N., Curry, S. et al. (2008). Treating tobacco use and dependence: 2008 update. Rockville, MD: Clinical Practice Guideline.

Franco, L., Welsby, D., Eccleston, P., \& Furber, S. (2011). A qualitative study about smoking cessation with clients of community service organisations that work with disadvantaged families. Health Promotion Journal of Australia: Official Journal of Australian Association of Health Promotion Professionals, 22(2), 153-155. Retrieved from https://search.informit.com.au/documentSummary;dn= 404349404698084;res=IELHEA.

Frost-Pineda, K., Muhammad-Kah, R., Rimmer, L., \& Liang, Q. (2014). Predictors, indicators, and validated measures of dependence in menthol smokers. Journal of Addictive Diseases, 33(2), 94-113. https://doi.org/10.1080/10550887. 2014.909696.

Haug, S., Meyer, C., Ulbricht, S., Schorr, G., Rüge, J., Rumpf, H.-J. et al. (2010). Predictors and moderators of outcome in different brief interventions for smoking cessation in general medical practice. Patient Education and Counseling, 78(1), 57-64. https://doi.org/10.1016/j.pec.2009.07.005.

Hollis, J. F., McAfee, T. A., Fellows, J. L., Zbikowski, S. M., Stark, M., \& Riedlinger, K. (2007). The effectiveness and cost effectiveness of telephone counselling and the nicotine patch in a state tobacco quitline. Tobacco Control, 16(Suppl. 1), i53i59. https://doi.org/10.1136/tc.2006.019794.

House, J. S., Landis, K. R., \& Umberson, D. (1988). Social relationships and health. Science, 241, 540-545.

Kviz, F. J., Crittenden, K. S., Clark, M. A., Madura, K. J., \& Warnecke, R. B. (1994). Buddy support among older smokers in a smoking cessation program. Journal of Aging and Health, 6, 229-254.

Lancaster, T., \& Fowler, G. (2000). Training health professionals in smoking cessation. In T. Lancaster (Ed.), Cochrane database of systematic reviews (pp. 1-16). Chichester, UK: John Wiley \& Sons, Ltd. https://doi.org/10.1002/14651858. CD000214.

Lancaster, T., \& Stead, L. F. (2005). Individual behavioural counselling for smoking cessation. In T. Lancaster (Ed.), Cochrane database of systematic reviews (pp. 1-75). Chichester, UK: John Wiley \& Sons, Ltd. https://doi.org/10.1002/ 14651858.CD001292.pub2.

Lancaster, T., Stead, L., Silagy, C., \& Sowden, A. (2000). Effectiveness of interventions to help people stop smoking: Findings from the cochrane library - ProQuest. British Medical Journal, 355-358. Retrieved from http://search.proquest. com/docview/1777606521?pq-origsite $=$ gscholar.

Lee, M., Miller, S. M., Wen, K.-Y., Hui, S. A., Roussi, P., \& Hernandez, E. (2015). Cognitive-behavioral intervention to promote smoking cessation for pregnant and postpartum inner city women. Journal of Behavioral Medicine, 38(6), 932-943. https://doi.org/10.1007/s10865-015-9669-7.

Mak, K.-K., Ho, S.-Y., \& Day, J. R. (2013). A review of life-course familial and lifestyle factors of smoking initiation and cessation. Current Cardiovascular Risk Reports, 7(6), 457-463. https://doi.org/10.1007/s12170-013-0341-x.

Mathur, S., \& Singh, N. (2015). Association of smoking cessation and intentions to quit: Role of occupational status, health professional's support, and perceived risk. Epidemiology, Biostatistics and Public Health, 12(1), 10910-10918. https://doi.org/10.2427/10910.

Meijer, E., Gebhardt, W. A., Laar, C. Van, Kawous, R., \& Beijk, S. C. A. M. (2016). Socio-economic status in relation to smoking: The role of (expected and desired) social support and quitter identity. Social Science \& Medicine, 162, 41-49. https://doi.org/10.1016/j.socscimed.2016.06.022.

Murray, R. P., Johnston, J. J., Dolce, J. J., Lee, W. W., \& O’Hara, P. (1995). Social support for smoking cessation and abstinence: The lung health study. Addictive Behaviors, 20(2), 159-170. https://doi.org/10.1016/S0306-4603(99)80001-X.

Patten, C. A., Goggin, K., Harris, K. J., Richter, K. P., Williams, K., Decker, P. A. et al. (2016). Relationship of autonomy social support to quitting motivation in diverse smokers. Addiction Research \& Theory, 24(6), 477-482. https://doi.org/ 10.3109/16066359.2016.1170815.

Rao, J. N. K., \& Scott, A. J. (1981). The analysis of categorical data from complex sample surveys: Chi-squared tests for goodness of fit and independence in two-way tables. Journal of the American Statistical Association, 76(374), 221. https://doi.org/10.2307/2287815. 
Rayens, M. K., Hahn, E. J., \& Hedgecock, S. (2008). Readiness to quit smoking in rural communities. Issues in Mental Health Nursing, 29(10), 1115-1133. https://doi.org/10.1080/ 01612840802319860.

Sarkar, S., Taylor, W. C., Lai, D., Shegog, R., \& Paxton, R. J. (2016). Social support for physical activity: Comparison of family, friends, and coworkers. Work, 55(4), 893-899. https: //doi.org/10.3233/WOR-162459.

SAS Institute Inc. (2014). SAS/STAT ${ }^{\circledR} 9.4$ user's guide. Cary, NC: SAS Institute Inc.

Schlam, T. R., Fiore, M. C., Smith, S. S., Fraser, D., Bolt, D. M., Collins, L. M. et al. (2016). Comparative effectiveness of intervention components for producing long-term abstinence from smoking: A factorial screening experiment. Addiction, 111(1), 142-155. https://doi.org/10.1111/add.13153.

Shiffman, S., Brockwell, S. E., Pillitteri, J. L., \& Gitchell, J. G. (2008a). Individual differences in adoption of treatment for smoking cessation: Demographic and smoking history characteristics. Drug and Alcohol Dependence, 93(1), 121-131. https://doi.org/10.1016/j.drugalcdep.2007.09.005.

Shiffman, S., Brockwell, S. E., Pillitteri, J. L., \& Gitchell, J. G. (2008b). Use of smoking-cessation treatments in the United States. American Journal of Preventive Medicine, 34(2), 102111. https://doi.org/10.1016/j.amepre.2007.09.033.

Sorensen, G., Emmons, K., Stoddard, A. M., Linnan, L., \& Avrunin, J. (2002). Do social influences contribute to occupational differences in quitting smoking and attitudes toward quitting? American Journal of Health Promotion: AJHP, 16(3), 135-141.

Soulakova, J. N., \& Crockett, L. J. (2016). Unassisted quitting and smoking cessation methods used in the United States: Analyses of 2010-2011 tobacco use supplement to the current population survey data. Nicotine \& Tobacco Research, 242(5), 273. https://doi.org/10.1093/ntr/ntw273.

Soulakova, J. N., Li, J., \& Crockett, L. J. (2017). Race/ethnicity and intention to quit cigarette smoking. Preventive Medicine Reports, 5, 160-165. https://doi.org/10.1016/j.pmedr.2016. 12.008 .

Steptoe, A., Shankar, A., Demakakos, P., \& Wardle, J. (2013). Social isolation, loneliness, and all-cause mortality in older men and women. Proceedings of the National Academy of
Sciences of the USA, 110(15), 5797-5801. https://doi.org/10. 1073/pnas.1219686110.

Tsoh, J. Y., Burke, N. J., Gildengorin, G., Wong, C. B., Le, K., Nguyen, A. et al. (2015). A social network family-focused intervention to promote smoking cessation in Chinese and Vietnamese American male smokers: A feasibility study. Nicotine \& Tobacco Research, 17(8), 1029-1038. https://doi. org/10.1093/ntr/ntv088.

Ubhi, H. K., Michie, S., Kotz, D., Wong, W. C., \& West, R. (2015). A mobile app to aid smoking cessation: Preliminary evaluation of SmokeFree28. Journal of Medical Internet Research, 17(1), e17. https://doi.org/10.2196/jmir.3479.

US Department of Commerce. US Census Bureau. (2012). National cancer institute-sponsored tobacco use supplement to the current population survey (2010-11). https://cancercontrol.cancer.gov/brp/tcrb/tus-cps/.

Technical documentation: https://www.census.gov/ programs-surveys/cps/technical-documentation/complet.

US Department of Commerce, US Census Bureau (2016). National cancer institute and food and drug administration co-sponsored tobacco use supplement to the current population survey (2014-15). https://cancercontrol. cancer.gov/brp/tcrb/tus-cps/. Technical documentation: https://www.census.gov/programs-surveys/cps/ technical-documentation/complete.html.

Villain, M., Sibon, I., Renou, P., Poli, M., \& Swendsen, J. (2017). Very early social support following mild stroke is associated with emotional and behavioral outcomes three months later. Clinical Rehabilitation, 31(311), 135-141. https://doi. org/10.1177/0269215515623600.

Zhou, X., Nonnemaker, J., Sherrill, B., \& Gilsenan, A. (2009). Attempts to quit smoking and relapse: Factors associated with success or failure from the ATTEMPT cohort study. Addictive Behaviors, 34(4), 365-373. Retrieved from http://www.sciencedirect.com/science/article/ pii/S0306460308003183.

Zhu, S., Melcer, T., Sun, J., Rosbrook, B., \& Pierce, J. P. (2000). Smoking cessation with and without assistance: A population-based analysis. American Journal of Preventive Medicine, 18(4), 305-311. Retrieved from http://www.ncbi. nlm.nih.gov/pubmed/10788733. 